\title{
Management of Root-Knot Disease on Tomato with Bioformulated Paecilomyces lilacinus and Leaf Extract of Lantana camara
}

\author{
Idorenyin Asukwo Udo ${ }^{*}$, Ephraim Onoku Osai and Donald Agioliwhu Ukeh (In memorian) \\ Department of Crop Science; University of Calabar; Calabar - Nigeria
}

\begin{abstract}
Glasshouse experiments were conducted to evaluate the efficacy of application frequency of a bioformulated Paecilomyces lilacinus in combination with five concentration of Lantana camara crude aqueous leaf extract against Meloidogyne incognita race I on tomato. The experiment was a $3 x 5$ factorial laid out in a completely randomized design (CRD) with four replications. Each seedling was inoculated with 5000 eggs of M. incognita. Application of the bionematicide and L. camara leaf extract alone significantly $(P \leq 0.05)$ inhibited root galling and egg production compared with their respective control. However, the severity of root galling and egg mass production was more significantly $(P<0.05)$ suppressed with the application of $\mathrm{P}$. lilacinus than $\mathrm{L}$. camara leaf extract. Double inoculation with P. lilacinus in combination with $0.80 \mathrm{~g} \mathrm{~mL}^{-1}$ of the L. camara leaf extract changed the susceptibility of the tomato cultivar with gall index $(G I=4.00)$ to $G I=1.50$. Application of P. lilacinus twice (at transplanting and two weeks after transplanting) in combination with $0.80 \mathrm{~g} \mathrm{~mL}^{-1}$ of $\mathrm{L}$. camara leaf extract was the most effective treatment in gall and egg mass inhibition, growth enhancement and dry matter accumulation. This environment-friendly approach could be incorporated into integrated root-knot disease management in tomato.
\end{abstract}

Key words: Biocontrol, Meloidogyne incógnita, Paecilomyces lilacinus, Lantana câmara, Tomato, botanical

\section{INTRODUCTION}

The cultivated tomato (Solanum lycopersicum L.) belongs to the family of Solanaceae, which includes crops such as eggplant, pepper, tobacco and potato. About 125 million tonnes of fresh tomatoes were produced in the world in 2008 (FAO 2010). China, the largest producer accounted for $25 \%$ of the global output followed by the United States and Turkey. The fruit is rich in vitamins $\mathrm{A}, \mathrm{C}$, thiamine, riboflavin, niacin as well as some minerals such as potassium and sodium (Smith 1994). Tomato antioxidant is known to prevent prostate cancer and improves the skin's ability to guard against harmful ultra- violet radiation (Rao and Rao 2007). The cultivation of tomato is limited by both biotic and abiotic stress factors. Poor yield of tomato in Nigeria has been attributed in part to root-knot diseases caused by Meloidogyne spp (Udo et al.2008; Ogwulumba et al. 2011).

Chemical control of nematode pests remains the most effective control measure but with some serious constraints. Chemical nematicides are very toxic to the mammals and beneficial soil micro fauna/flora, pollute groundwater and have residual effect on farm produce. The use of plant extracts and antagonistic microorganisms as a component of integrated nematode management is fast gaining wide acceptance. The fungus,

*Author for correspondence: idyudo@gmail.com 
Paecilomyces lilacinus (Thom) Samson has been reported as a good bicontrol agent of root-knot nematodes and other plant parasitic nematodes (Cabanillas and Barker 1989; Oclarit and Cumagun 2009; Hashem and Abo-Elyours 2011; Udo et al. 2013). Similarly, the tropical weed, Lantana camara L. Sensu lato (Lantana, Verbanaceae) has been identified to possess nematicidal constituents that suppress the growth and reproduction of various species of Meloidogyne (Shaukat and Siddiqui 2001 ; Qamar et al. 2005; Begum et al. 2008; Ahmad et al. 2010). The weed is a highly invasive shrub in some tropical countries like South Africa of which biological control measures are currently being evaluated (Urban et al. 2011). This study was carried out to evaluate the individual and combined effects of $L$. camara aqueous leaf extract and a bioformulated $P$. lilacinus on the pathogenicity of $M$. incognita race I on tomato.

\section{MATERIALS AND METHODS}

\section{Experimental site and source of material}

The experiment was conducted in the glasshouse of the Faculty of Agriculture, University of Calabar, Cross River State, Nigeria between May and September, 2011. Seeds of the test plant, tomato cv. Roma VF were obtained from the National Horticultural Research Institute (NIHORT), Ibadan, Nigeria. A bioformulation containing $P$. lilacinus as the active ingredient with trade name PL Gold ${ }^{\mathrm{TM}}$ was obtained from the Biological Control Products, South Africa (Pty) Ltd. It is a wettable powder spore concentrate of $P$. lilacinus, a fungal nematicide with an active ingredient of $4 \times 10^{9}$ spores gram $^{-1}$ used with a Gold starter (Fungal spore activator). L. camara was sourced from a fallow land beside the Visual Art Department, Cross River University of Technology, Calabar.

\section{Building up of nematode population/ inoculum preparation}

A pure stock culture of $M$. incognita race I maintained on Celosia argentia was multiplied on a susceptible tomato cv. Roma VF in the glasshouse in a steam-sterilized sandy loam soil. Heavily galled roots of the tomato plants were uprooted eight weeks after transplanting and washed clean with running tap water. The galled roots were cut into $1-2 \mathrm{~cm}$ segments for egg extraction with $0.50 \%$ sodium hypochlorite solution according to the method of Hussey and Barker (1973). The inoculum density was adjusted to 500 eggs $\mathrm{mL}^{-1}$ of the egg suspension.

\section{Preparation of the $L$. camara leaf extract and Paecilomyces lilacinus inoculum}

Fresh green leaves of L. camara were harvested and thoroughly washed, chopped into pieces and then ground into a paste. The ground leaf was weighed as 200, 400, 600 and $800 \mathrm{~g}$ into separate plastic buckets. One litre $(1000 \mathrm{ml})$ of distilled water was added to each container, and allowed to stand for $24 \mathrm{~h}$. It was then filtered through a double-fold muslin cloth. Thus, the filtrate had concentration of $0.20,0.40,0.60$, and $0.80 \mathrm{~g} \mathrm{~mL}^{-1}$ respectively. Fifty grams of the spore powder of the bionematicide (PL Gold ${ }^{\mathrm{TM}}$ ) was mixed with $50 \mathrm{ml}$ of the spore activator (mixture ratio of $1: 1$, $\mathrm{V} / \mathrm{V}$ ) and allowed to stand for an hour before further dilution with 30 litres of distilled water.

\section{Application of treatments}

Surface soil $(0-15 \mathrm{~cm})$ was collected from a fallow land in the Crop Science Teaching and Research Farm. The composite soil sample was analyzed for its physicochemical properties and pre-plant nematode density using the methods of Tel and Rao (1982) and Coyne et al. (2007), respectively. Sixty plastic pots with diameter $15 \mathrm{~cm}$ and depth $25 \mathrm{~cm}$ perforated at the bottom were filled each with $3.0 \mathrm{~kg}$ of unsterilized top soil. Four-week-old tomato seedling (cv. Roma VF) raised in steamsterilized soil was transplanted to each pot. Each seedling was inoculated with 5,000 eggs of $M$. incognita by pouring $10 \mathrm{~mL}$ of the prepared inoculum into three holes made around each stand. The seedlings were also inoculated with $30 \mathrm{ml}$ of the spore mixture of the bionematicide (i.e., $0.05 \mathrm{~g}$ spore powder plant ${ }^{-1} \equiv 2 \times 10^{8}$ spores plant $^{-1}$ ). Treatments that required double application of the bionematicide were inoculated in the same manner two weeks after transplanting. At the same time, L. camara leaf extract was applied at the rate of $10 \mathrm{~mL}$ per pot for each concentration. Equal volume of water was applied to the pots that served as control. The plants were watered appropriately and allowed to grow for six weeks with a mean day temperature of $28+2{ }^{\circ} \mathrm{C}$. The first trial was conducted between May and July 2011 and was repeated between July and September of the same year. 


\section{Experimental design and data collection}

The experiment was laid out as a $3 \times 5$ factorial in a completely randomized design (CRD) with four replications. The frequency of bionematicide application (no application, applied once at transplanting and applied twice, i.e., at transplanting and two weeks later) was combined in a factorial fashion with the five concentration of L. camara leaf extract $(0.00,0.20,0.40,0.60$ and. $80 \mathrm{~g} \mathrm{~mL}^{-1}$ ) to give 15 treatment combinations. At six weeks after transplanting, the following data were collected; number of galls and egg masses per root system, fresh and dry weight of root and shoot per plant. Shoot length and number of leaves per plant were recorded at four and six weeks after transplanting. For egg mass count, fresh root was stained in $20 \%(\mathrm{v} / \mathrm{v})$ solution of McCormick schilling red food colour stain (McCormick and Co. Inc., Hunt Valley, MD) according to the procedure outlined by Thies et al. (2002). Root gall index was determined on a 0-5 scale rating according to Taylor and Sasser (1978).

\section{Data analysis}

A two-way analysis of variance (ANOVA) was used to test the significance of the treatments. Significant treatment means were separated using Fisher's least significant difference (F-LSD) at 5\% level of probability. All the statistical analyses were performed with GENSTAT $8^{\text {th }}$ edition, statistical software. The results of the two trials were pooled since there was no statistical significant difference between the trials.

\section{RESULTS AND DISCUSSION}

Results of the physicochemical properties of the soil used for the experiment indicated that it was sandy loam in texture, strongly acidic $\mathrm{pH}_{\mathrm{w}}=5.20$, low in exchangeable cations, organic matter but with high available phosphorus $\left(46.0 \mathrm{mg} \mathrm{kg} \mathrm{kg}^{-1}\right)$. The pre-plant nematode density was 156 larvae $200 \mathrm{~cm}^{-3}$ of soil. Root galling and egg production were significantly $(\mathrm{P} \leq 0.05)$ inhibited with the application of $L$. camara leaf extract (Table 1).

Table 1 - Effects of different concentrations of Lantana camara leaf extracts and Paecilomyces lilacinus on Gall Index (GI)* and no. of egg masses/root system of tomato plant infected with M. incognita.

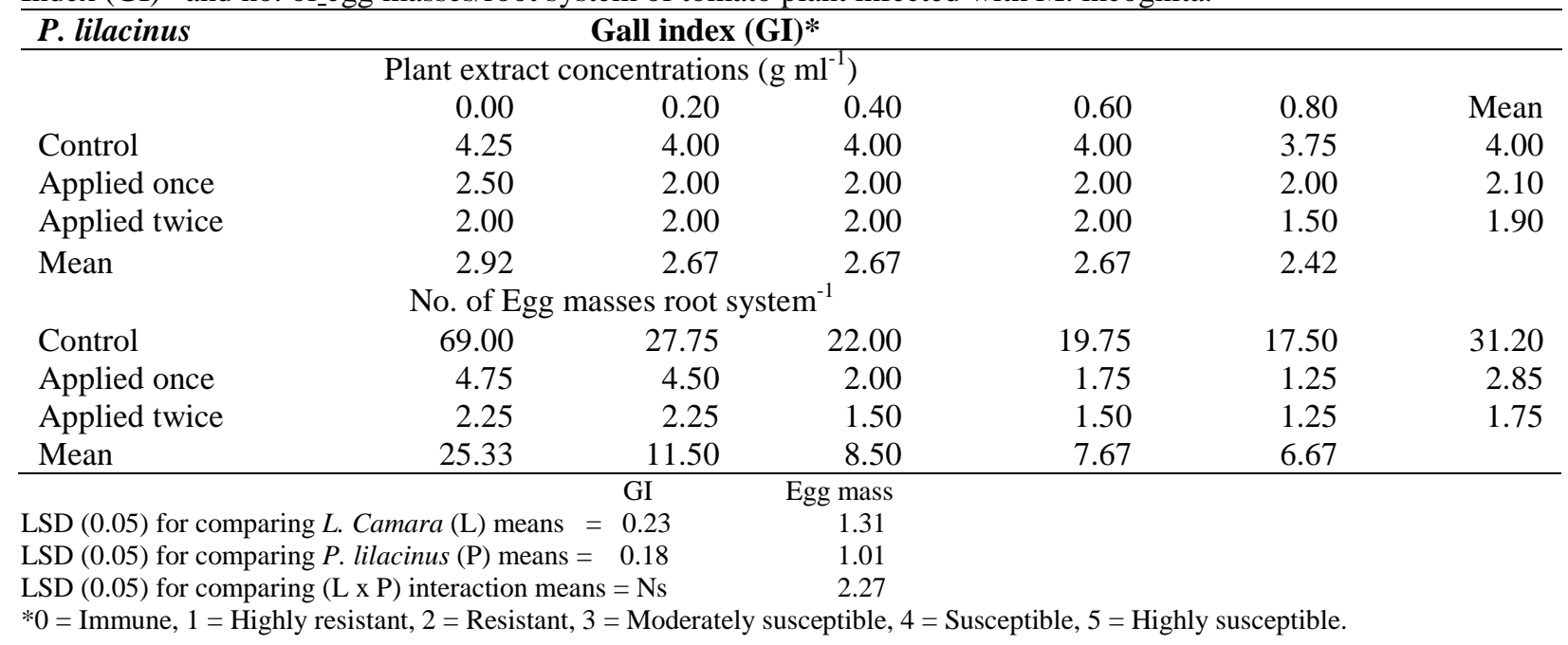

However, there were no significant $(\mathrm{P}>0.05)$ differences in root gall index among the concentrations of leaf extract 0.20 to $0.60 \mathrm{~g} \mathrm{~mL}^{-1}$. Increase in the concentration of the extract beyond $0.60 \mathrm{~g} \mathrm{~mL}^{-1}$ did not cause any significant decrease in egg production by $M$. incognita. Application of the bionematicide reduced the gall index (GI) from 4.00 (Susceptible) to 2.00 (Resistant). Egg production was significantly reduced with double application of the bionematicide. There was a significant $(\mathrm{P} \leq 0.05)$ interaction between the two factors. The combination of double application of the bionematicide with $0.08 \mathrm{~g} \mathrm{~mL}^{-1}$ L. camara leaf extract reduced gall index and number of eggmasses per root system to 1.50 and 1.25, respectively.

These findings validated the report of earlier investigators. About ten nematicidal constituents have been isolated and characterized from the aerial parts of L. camara (Shaukat et al. 2003, 
Qamar et al. 2005; Begum et al. 2008; Ahmad et al. 2010). The basic component is pentacyclic triterpenoid which has Camarolic acid, Pomolic acid, Lantanolic acid,Lantrigloylic acid, Lantoic acid, Ursolic acid, Camarin, Lantacin and Camarinin. In both In vitro and In vivo trials, leaf extract of $L$. camara have been implicated in the mortality and immobility of larvae of Meloidegyne spp, inhibition of egg hatch, growth and reproduction. In most of those trials, the active components were reported to exhibit the nematicidal property at higher concentration and nematostatic property at lower concentration. Ahmad et al. (2010) observed 96\% mortality of $M$. incognita juveniles $\left(\mathrm{J}_{2}\right)$ exposed to $0.33 \mathrm{~g} \mathrm{~mL}^{-1}$ leaf extract of $L$. camara after 24 h but $75 \%$ mortality at $0.165 \mathrm{~g} \mathrm{~mL}^{-1}$ after $48 \mathrm{~h}$. They also reported protection of the roots of eggplant from nematode attack with the application of leaf extracts of $L$. camara. Nematostatic properties of $L$. camara leaf extract were attributed to poor coordination and orientation of infective juveniles towards the plant roots. The present results clearly illustrated nematicidal activity of aqueous leaf extract of $L$. camara against $M$. incognita as indicated by the reduced galling and egg production at higher concentration. P. lilacinus is a facultative parasitic fungus of root-knot nematode eggs. The efficacy of the fungus was higher with double application than single application confirming the report of Cabanillas and Barker (1989) and Udo et al. (2013). Results of fresh and dry root weight, shoot length, number of leaves and shoot dry matter/plant are presented in Tables 2, 3, 4 and 5, respectively.

Table 2 - Effect of different concentrations of L. camara leaf extract and Paecilomyces lilacinus on fresh and dry root weight $(\mathrm{g})$ per tomato plant infected with $M$. incognita.

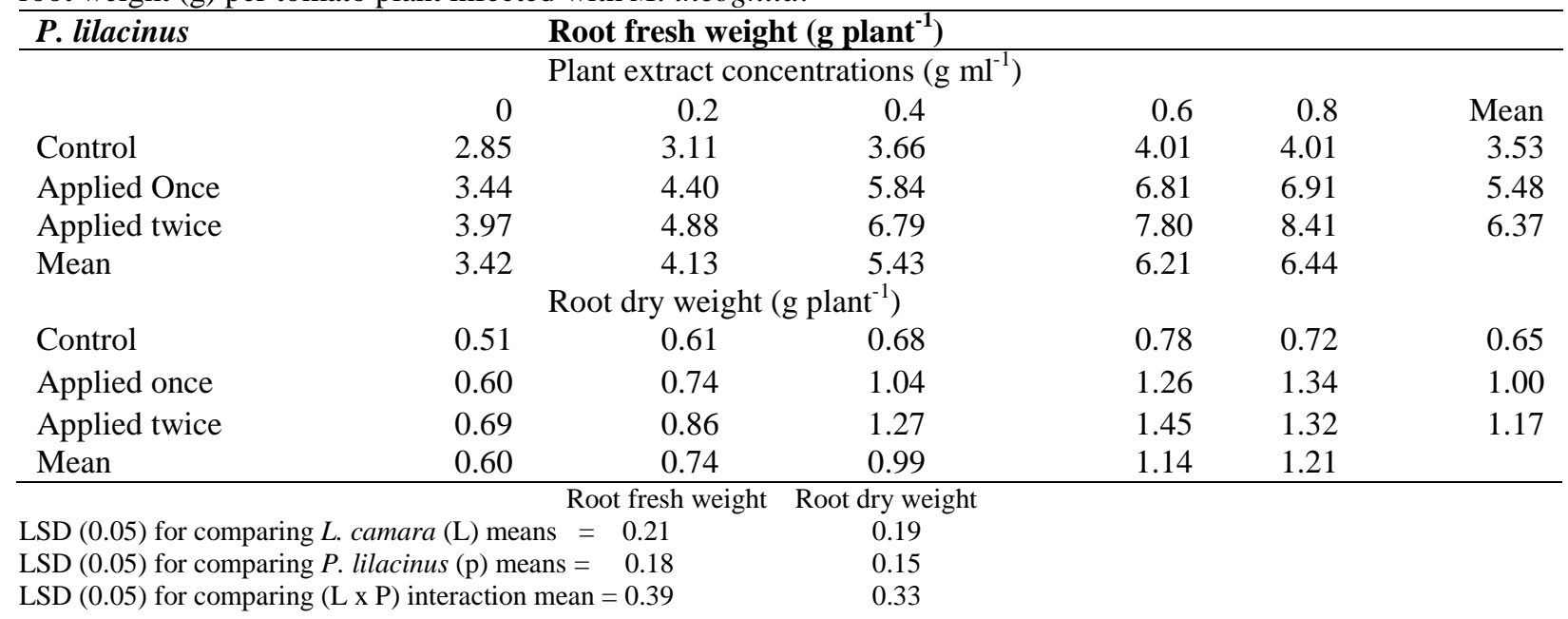

Table 3 - Effects of different concentrations of Lantana camara leaf extracts and Paecilomyces lilacinus on plant height $(\mathrm{cm})$ per plant of tomato infected with M. incognita at 4 and 6 WAT.

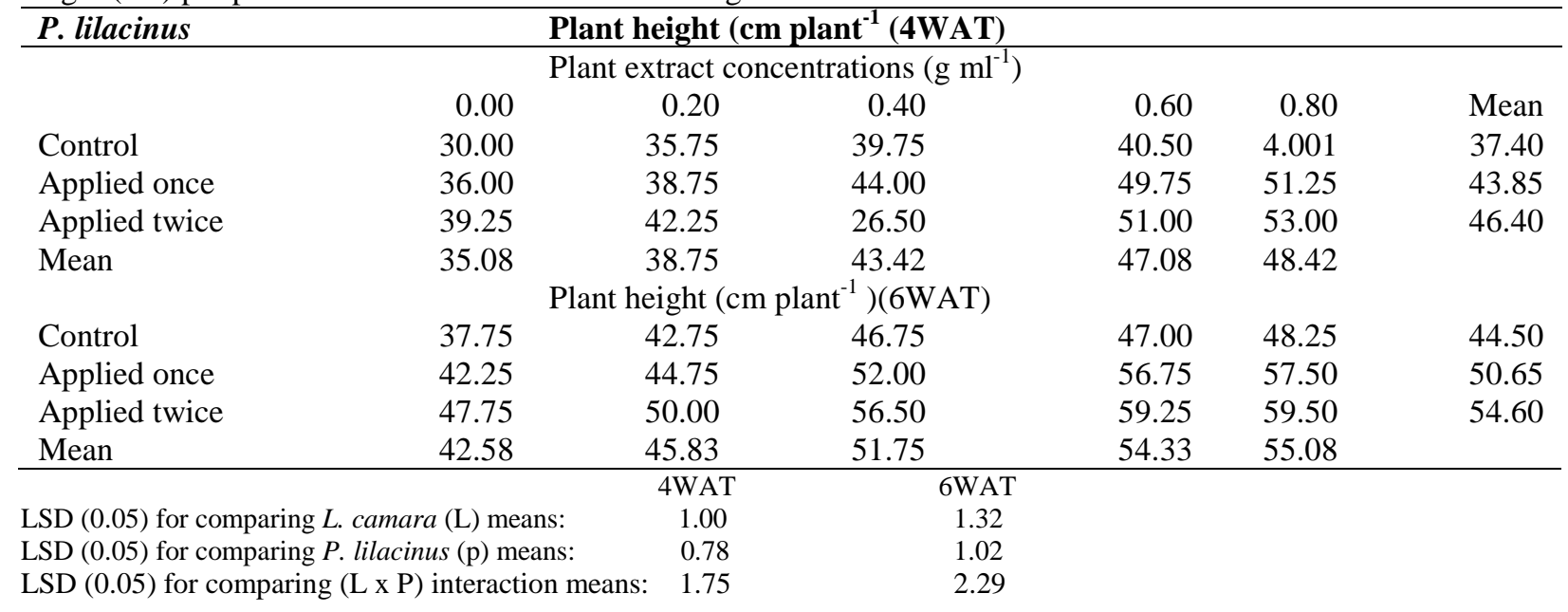


Table 4 - Effects of different concentrations of L. camara leaf extracts and Paecilomyces lilacinus on the number of leaves per plant of tomato infected with M. incognita at 4WAT and 6WAT.

\begin{tabular}{|c|c|c|c|c|c|c|}
\hline \multirow[t]{3}{*}{ P. lilacinus } & & aber of 1 & $\mathrm{nnt}^{-1}(4$ & & \multirow[b]{3}{*}{0.80} & \multirow[b]{3}{*}{ Mean } \\
\hline & & t extract & ations ( & & & \\
\hline & 0.00 & 0.20 & 0.40 & 0.60 & & \\
\hline Control & 9.50 & 9.75 & 11.50 & 11.50 & 11.50 & 10.75 \\
\hline Applied once & 10.25 & 13.00 & 14.50 & 14.00 & 15.50 & 13.45 \\
\hline Applied twice & 12.25 & 13.75 & 15.25 & 16.25 & 17.75 & 15.05 \\
\hline \multirow[t]{2}{*}{ Mean } & 10.67 & 12.17 & 13.75 & 13.92 & 14.92 & \\
\hline & \multicolumn{4}{|c|}{ Number of leaves plant ${ }^{-1}$ (6WAT) } & & \\
\hline Control & 12.50 & 12.50 & 13.25 & 13.50 & 12.50 & 12.85 \\
\hline Applied once & 13.25 & 15.25 & 16.25 & 15.25 & 17.50 & 15.50 \\
\hline Applied twice & 15.00 & 15.75 & 16.50 & 18.00 & 19.50 & 16.95 \\
\hline \multirow[t]{2}{*}{ Mean } & 13.58 & 14.50 & 15.33 & 15.58 & 16.50 & \\
\hline & & 4WAT & $6 \mathrm{WA}^{7}$ & & & \\
\hline $\operatorname{LSD}(0.05)$ for $\mathrm{co}$ & & $=0.59$ & 0.63 & & & \\
\hline $\operatorname{LSD}(0.05)$ for com & $s(\mathrm{p}) \mathrm{me}$ & & 0.47 & & & \\
\hline LSI & 17 & 1.03 & 1.05 & & & \\
\hline
\end{tabular}

Table 5 - Effect of different concentrations of Lantana camara leaf extract and Paecilomyces lilacinus on fresh and dry shoot weight $\left(\mathrm{g}\right.$ plant $\left.{ }^{-1}\right)$ of tomato infected with $M$. incognita.

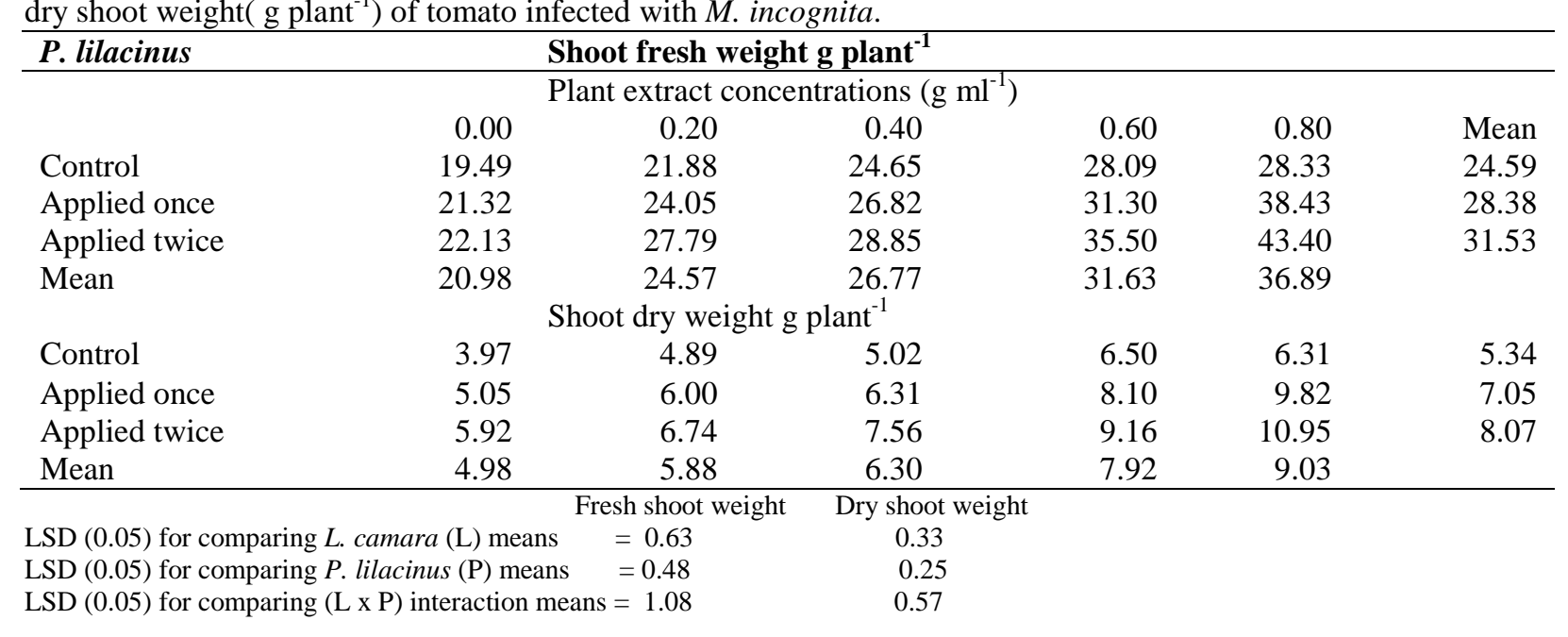

Generally, there was a significant $(\mathrm{P} \leq 0.05)$ increase in the growth, leaf production and dry matter accumulation in tomato plants with increase in the concentration of aqueous leaf extract of $L$. camara as well as application frequency of the bionematicide. The two factors interacted positively. The tallest plants, highest leaf number and dry matter production were obtained when the bionematicide was applied two times in combination with $0.80 \mathrm{~g} \mathrm{~mL}^{-1}$ of the L. camara leaf extract.

These findings illustrated that the leaf extract of $L$. camara at the highest concentration of $0.80 \mathrm{~g} \mathrm{~mL}^{-1}$ was not phytotoxic to tomato plants and had no adverse effect on the parasitic fungus, $P$. lilicinus, thus nullifying the findings of Ahmad et al.
(2010). Shaukat et al. (2003) also demonstrated the compatibility of concentrated root leachets of $L$. camara with the bacterium (Pseudomonas aurignosa) in the management of some plant parasitic nematodes.

The improvement in the growth and dry matter production in the plants treated with higher concentration of leaf extract of $L$. camara and double inoculation of the bionematicide was a reflection of the suppressive effects of these control agents on $M$. incognita. Galled roots were inefficient in water and nutrients absorption and translocation. There was also a general disruption of many physiological functions in which assimilate production and translocations were impaired. Thus, tomato plants whose roots were 
lightly parasitized by the root-knot nematode species were able to grow and accumulate reasonable dry matter. The metabolic activities of an economic plant are reflected in its dry weight, growth and yield. The reduction in biomass of the heavily galled plants indicated a decrease in metabolic activities.

\section{CONCLUSION}

The study revealed that higher concentration of the aqueous leaf extract of L. camara was needed for significant inhibition of root galling and egg production by $M$. incognita race 1 on a susceptible tomato cultivar. Application of the bioformulated $P$. lilacinus once or two times was effective in reducing the galling and egg production by the nematode species. The two control agents were compatible as the greatest gall and egg mass suppression, growth enhancement and dry matter yield were obtained at $0.80 \mathrm{~g} \mathrm{~mL}^{-1}$ of the leaf extract in combination with double application of the bionematicide. This eco-friendly approach in the management of root-knot disease of tomato could be adopted after proper identification of the nematicidal constituents of the leaf extract of $L$. camara and field trials of the efficacy of both biocontrol agents.

\section{ACKNOWLEDGEMENTS}

The authors wish to thank the Biological Control Products South Africa (Pty.) Ltd. for allowing their product to be tested in Nigeria. The cooperation by the Nigeria Plant Quarantine Service in the procurement of PL Gold ${ }^{\mathrm{TM}}$ is also acknowledged. Special thanks to Otobong Cyril Etim for his technical assistance.

\section{REFERENCES}

Ahmad F, Rather MA, Siddiqui MA. Nematicidal activity of leaf extract from Lantana camara $L$. against Meloidogyne incognita (Kofoid and white) chitwood and its use to manage root infection of Solanum melongena L. Braz Arch Biol Technol. 2010; 53(3): 543-548.
Begum S, Zehra SQ, Siddiqui BS, Fayyaz S, Ramzan M. Pentacyclic Triterpenoids from the aerial parts of Lantana camara and their nematicidal activity. Chemistry and Biodiversity. 2008; 5: 1856-1866.

Cabanillas, ER, Barker KR. Impact of Paecilomyces lilacinus inoculum level and application time on control of Meloidogyne incognita on tomato. $J$ Nematol. 1989; 21(1): 115-120.

Coyne DL, Nicol JM, Claudis-Cole B. Practical plant nematology: a field and laboratory guide: Cotonou, Benin: SP-IPM secretariat, International Institute of Tropical Agriculture (IITA); 2007.

Food and Agricultural Organization (FAO). FAO production year book for 2008. Rome, Italy: FAO; 2010.

Hashem M, Abo-Elyousr KA. Management of the rootknot nematode Meloidogyne incognita on tomato with combination of different biocontrol organisms. Crop Prot. 2011; 30: 285-292.

Hussey RS, Barker KR. A comparison of methods of collecting inocula of Meloidogyne spp including new technique. Plant Dis Reptr. 1973; 57: 1025-1028.

Oclarit EL, Cumagun CJR. Evaluation of the efficacy of Paecilomyces lilacinus as biological control agent of Meloidogyne incognita attacking tomato. J Plant Prot Res. 2009; 49(4) 337-340.

Ogwulumba SI, Ugwuoke, KI, Ogbuji, RO. Reaction of tomato cv. Roma VF (Solanum lycopersicum) to Meloidogyne javanica Treub. infestation in an Ultisol treated with aqueous leaf extracts of bitter leaf (Vernonia amygdaline L. ) and Mango (Magnifera indica L.) J Plant Prot Res. 2011;51(1): 14-17.

Qamar F, Begum S, Raza SM, Wahab A, Siddiqui BS. Nematicidal natural products from the aerial parts of Lantana camara L. Nat Prod Res. 2005; 19: 609-613.

Rao AV, Rao LG. Carotenoids and human health. Pharm Res. 2007; 55(3): 207-216.

Shaukat SS, Siddiqui IA. Lantana camara in the soil changes the fungal community structure and reduces impact of Meloidogyne javanica on mungbean. Phytopathol Med. 2001; 40(2): 245-252.

Shaukat SS, Siddiqui IA, Ali NT, Ali SA, Khan G. Nematicidal and allelopathic responses of Lantana camara root extract Phytopathol Med. 2003; 42(1): 71-78.

Smith AF. The tomato in America. London: University of Ilinois Press; 1994.

Taylor AI, Sasser JN. Biology, identification and control of root-knot nematodes (Meloidogyne species). Raleigh, NC: Department of plant pathology North Carolina State University and US Agency for International Development; 1978.

Tel DA, Rao P. Automated and semiautomated method for soil and plant analysis. Manual series No. 7, IITA, Ibadan, Nigeria; 1982. 
Thies JA, Merrill SB, Corley EL. Red food colouring stain: New, safer procedures for staining nematodes in roots and egg masses on root surfaces. $J$ Nematol. 2002; 34(2): 179-181.

Udo IA, Uguru MI, Ogbuji RO, Ukeh DA. Sources of tolerance to root-knot nematode, Meloidogyne javanica in cultivated and wild tomato species. Plant Pathol J. 2008; 7(1): 40-44.

Udo IA, Uguru MI, Ogbuji RO. Pathogenicty of Meloidogyne incognita race 1 on tomatoes as influenced by different arbuscular mycorrhizal fungi and bioformulated Paecilomyces lilacinus in a Dysteric cambisol soil. J Plant Prot Res. 2013; 53(1): 71-78.
Urban AJ, Simelane DO, Retief E, Heystek F, Williams HE, Madine LG. The invasive Lantana camara. $L$. Hybrid Complex (Verbanaceae); A review of research into its identity and biological control in South Africa. African Enotomol. 2011; 19(2): 315348.
Received: June 24, 2013; Accepted: December 23, 2013. 